\title{
GENDER DIFFERENCE IN PSYCHIATRIC MORBIDITY AMONG INMATES OF JUVENILE HOMES
}

\author{
Ganga Gangadhara Kaimal', Madhavy Sukumaran Razeena Padmam²
}

${ }^{1}$ Assistant Professor, Department of Psychiatry, Government T. D. Medical College, Alappuzha.

${ }^{2}$ Retd. Director, Department of Behavioural Medicine, School of Behavioural Sciences, M. G. University, Kottayam.

\section{ABSTRACT}

\section{BACKGROUND}

Mental health problems are found to be high among institutionalised children. Delinquent behaviours in children can occur as a part of psychiatric disorders. Understanding the mental health disorders among children living in institutions like juvenile homes will help to make policies to meet their needs.

\section{MATERIALS AND METHODS}

100 children and adolescents from juvenile home in Kerala were selected for the study. After getting ethical clearance and permission from the concerned authorities, children who chose to participate signed a consent form. Personal data of children was collected using a personal data sheet. The investigator interviewed each of the participant individually to assess psychopathology, and Psychiatric disorders were diagnosed based on ICD-10. Chi-square test was used for statistical analysis.

\section{RESULTS}

Out of the 100 children assessed, 42 percent were found to have Psychiatric illness. $46.6 \%$ of the boys and $29.6 \%$ of the girls were found to have Psychiatric illness which indicates that there is a significant difference among the boys and girls having Psychiatric illness.

\section{CONCLUSION}

Psychiatric morbidity is high among inmates of juvenile homes and boys are having more psychiatric morbidity than girls.

\section{KEYWORDS}

Juvenile Home, Psychiatric Morbidity, Gender Difference.

HOW TO CITE THIS ARTICLE: Kaimal GG, Padmam MSR. Gender difference in psychiatric morbidity among inmates of juvenile homes. J. Evolution Med. Dent. Sci. 2017;6(78):5527-5530, DOI: 10.14260/jemds/2017/1201

\section{BACKGROUND}

As per the World Health Organization (WHO), mental health disorders are one of the leading causes of disability worldwide. The burden of mental disorders continues to grow with significant impacts on health and major social, human rights and economic consequences in all countries of the world. Psychiatric disorders are common during childhood and adolescence. In the Isle of Wight (IOW) study, Rutter et al $^{1}$ (1970) found prevalence rates of around 7\% among $10-11$ year old children. Followup of these children into adolescence found that more than $40 \%$ of the children with conduct disorder continuing with major problems. Emotional disorders were more common among girls with anxiety as the most common type. Another longitudinal community study conducted (Costello EJ, Mustillo S, Erkanli A, Keeler G, Angold A., 20032) to assess the prevalence and development of psychiatric disorders from age 9 through 16 years found that $31 \%$ of girls and $42 \%$ of boys had at least 1 psychiatric disorder. An epidemiological study (Mousa Thabet AA1, Vostanis P., 20013) on child mental health problems in Gaza Strip revealed $54.5 \%$ of boys and $46.5 \%$ of girls were having behavioural and emotional problems and

'Financial or Other Competing Interest': None.

Submission 31-07-2017, Peer Review 16-09-2017,

Acceptance 21-09-2017, Published 28-09-2017.

Corresponding Author:

Ganga G. Kaimal,

Assistant Professor of Psychiatry,

Government T. D. Medical College, Alappuzha.

E-mail: gangagkaimal@gmail.com

DOI: $10.14260 /$ jemds $/ 2017 / 1201$ the differences between boys and girls were statistically significant. An Indian study conducted in Pondicherry on childhood psychiatric disorders (Premarajan KC, Danabalan M, Chandrasekhar R, Sreenivasa DK, 1993) ${ }^{4}$ reported a prevalence rate of 58.6/1000 in children of 0-12 age group. Among these, boys had a prevalence of $68.7 / 1000$ and girls had 49.3/1000. Another study conducted in Kerala among 1403 children in the age group of 8-12 years by Hackett R, Hackett L, Bhakta P, Gowers S. (1999) ${ }^{5}$ found a projected prevalence of $9.4 \%$. Externalising disorders were found to be more in boys and found to be associated with adverse social conditions.

Children and youth are the most important resources of any country. Healthy growth and development of children is the responsibility of the society. In India, the laws relating to children who need care and protection and who conflict with law is the Juvenile Justice Act (Care and Protection of Children), 2000. Juvenile homes are institutions established under this act, which are meant for children who need care and protection. Shelter, food, education, medical care, rehabilitation, developmental opportunities and exposure for socialisation/mainstreaming are the services provided in Juvenile Homes. Studies have shown that psychiatric disorders are high among detained juveniles. A large epidemiological study of detained juveniles in the United States $(\mathrm{N}=1,829)$ conducted in $2002^{6}$ reported that as many as two thirds of males and three quarters of females meet criteria for one or more psychiatric disorders (Teplin, Abram, McClelland, Dulcan \& Mericle, 2002). In another study conducted in Kenya by Maru HM, Kathuku DM, and Ndetei DM (2003),7 it was found that the crude psychiatric morbidity rate was $44.4 \%$. An 
Indian cross-sectional study conducted in an observation home for boys (Bhoge ND, Panse SN, Pawar AV, Raparti GT, Ramanand JB, Ramanand SJ, 20178) found 88\% of inmates had Psychiatric Diagnosis as per ICD-10 DCR guidelines.

In a large-scale survey of youth in residential placement, Sedlak and McPherson $(2010)^{9}$ concluded that despite great needs, mental health and educational services are deficient for many youths. Understanding the psychiatric disorders of juvenile detainees is an important step toward meeting their needs. The present study intends to identify the gender difference in Psychiatric morbidity among the inmates of juvenile homes.

\section{Objectives}

1. To identify the prevalence of Psychiatric morbidity among inmates of juvenile homes.

2. To identify the type of psychiatric illness among inmates of juvenile homes.

3. To identify whether there is any gender difference in Psychiatric morbidity among inmates of juvenile homes.

\section{MATERIALS AND METHODS}

Study Design- Cross-sectional study.

Sample- The sample consists of 100 children and adolescents from juvenile homes in Kerala. Sample size is decided to be of 100 children for convenience.

\section{Tools}

a. Personal data sheet- Developed by the investigator.

b. International Classification of Diseases -10 .

\section{Procedure}

There are 9 children's homes and 14 observation homes in the state of Kerala which are established under Juvenile Justice Act 2000. Among these, 20 homes are for boys and 3 are for girls. After getting ethical clearance, from the 20 homes for boys, 3 homes are selected and from the 3 homes for girls, one is selected by stratified random sampling. After getting permission from the concerned authorities, all the inmates of the girl's home are included in the study which constitute 27 children. A total of 79 inmates are present in 3 homes for boys. Among them, 73 children are selected by simple random sampling. Personal data of children is collected using a personal data sheet. The investigator interviewed each of the participant individually to assess psychopathology and Psychiatric disorders were diagnosed based on ICD-10. Chisquare test is used for statistical analysis.

\section{RESULTS}

Out of the 100 children assessed, 42 children were found to have psychiatric illness. Among these 42 children, 14 children were suffering from behavioural disorder, 11 were suffering from emotional disorder, 9 were suffering from substance use disorder, 4 each were suffering from developmental disorder, and other disorders. $46.6 \%$ of the boys and $29.6 \%$ of the girls were having Psychiatric illness. Two-way classification between gender and psychiatric morbidity and the independent sample chi-square test is used to ascertain gender difference in the psychiatric morbidity. The results suggest that there is a significant difference between the boys and girls having Psychiatric illness. Among the Psychiatric illnesses, behavioural disorders and substance use disorders were found to be more in boys and emotional disorders were found to be more in girls.

Age Distribution of Children

Of the 100 children, 14 were between 8-12 years of age and 86 were between 13-18 years of age.

\begin{tabular}{|c|c|c|}
\hline & Frequency & Percent \\
\hline $8-12$ Years & 14 & 14.0 \\
\hline $13-18$ Years & 86 & 86.0 \\
\hline Total & $\mathbf{1 0 0}$ & $\mathbf{1 0 0 . 0}$ \\
\hline \multicolumn{2}{|c|}{ Table 1. Age Distribution } \\
\hline
\end{tabular}

Gender Distribution of Children

Of the 100 children, there were 73 boys and 27 girls.

\begin{tabular}{|c|c|c|}
\hline Gender & Frequency & Percent \\
\hline Male & 73 & 73.0 \\
\hline Female & 27 & 27.0 \\
\hline Total & $\mathbf{1 0 0}$ & $\mathbf{1 0 0 . 0}$ \\
\hline \multicolumn{2}{|c|}{ Table 2. Gender Distribution } \\
\hline
\end{tabular}

\section{Prevalence of Psychiatric Illness}

42 percent of the inmates were found to have Psychiatric illness.

\begin{tabular}{|c|c|c|}
\hline Psychiatric illness & Frequency & Percent \\
\hline Present & 42 & 42.0 \\
\hline Absent & 58 & 58.0 \\
\hline Total & $\mathbf{1 0 0}$ & $\mathbf{1 0 0 . 0}$ \\
\hline \multicolumn{2}{|c|}{ Table 3. Psychiatric Illness } \\
\hline
\end{tabular}

Gender difference in the Prevalence of Psychiatric Illness Out of the 100 children assessed, 34 boys (46.6\%) and 8 girls (29.6\%) were found to have Psychiatric illness.

\begin{tabular}{|c|c|c|c|c|c|}
\hline & Present & Absent & Total & Chi square & P value \\
\hline Boys & $\begin{array}{c}34 \\
(46.6 \%)\end{array}$ & $\begin{array}{c}39 \\
(53.4 \%)\end{array}$ & $\begin{array}{c}73 \\
(100 \%)\end{array}$ & \multirow{3}{*}{1.680} & \multirow{3}{*}{0.195} \\
\hline Girls & $\begin{array}{c}8 \\
(29.6 \%)\end{array}$ & $\begin{array}{c}19 \\
(70.4 \%)\end{array}$ & $\begin{array}{c}27 \\
(100 \%)\end{array}$ & & \\
\hline Total & 42 & 58 & 100 & & \\
\hline \multicolumn{6}{|c|}{ Table 4. Gender and Psychiatric Illness } \\
\hline
\end{tabular}

\section{Type of Psychiatric Illness}

Among the 42 children who were found to have psychiatric illness, 14 were suffering from behavioural disorder, 11 were suffering from emotional disorder, 9 were suffering from substance use disorder 4 each were suffering from developmental disorder, and other disorders (mania, psychosis).

\begin{tabular}{|c|c|}
\hline Type of Psychiatric Illness & Number \\
\hline Behavioural Disorder & $14(33.3 \%)$ \\
\hline Emotional Disorder & $11(26.2 \%)$ \\
\hline Substance use Disorder & $9(21.4 \%)$ \\
\hline Developmental Disorder & $4(9.5 \%)$ \\
\hline Others & $4(9.5 \%)$ \\
\hline \multicolumn{2}{|c|}{ Table 5. Type of Psychiatric Illness } \\
\hline
\end{tabular}




\section{Gender and Type of Psychiatric Illness}

Behavioural disorders and substance use disorders were more in boys than in girls. $35.3 \%$ of boys were found to have behavioural disorder and $25 \%$ of girls were also having behavioural disorders. 8 boys (23.6\%) were having substance use disorder whereas only 1 girl (12.5\%) was found to be suffering from substance use disorder. Emotional disorders were more in girls. $37.5 \%$ of girls and $23.5 \%$ of boys were suffering from emotional disorders. Developmental disorders were found in 3 boys (8.8\%) and 1 girl (12.5\%). Others include 2 boys with psychotic disorder, one girl with hypomanic episode and 1 boy with manic episode.

\begin{tabular}{|c|c|c|c|c|c|c|}
\hline Gender & $\begin{array}{c}\text { Emotional } \\
\text { Disorder }\end{array}$ & $\begin{array}{c}\text { Behavioural } \\
\text { Disorder }\end{array}$ & $\begin{array}{c}\text { Developmental } \\
\text { Disorder }\end{array}$ & $\begin{array}{c}\text { Substance use } \\
\text { Disorder }\end{array}$ & 0thers & Total \\
\hline Boys & $8(23.5 \%)$ & $12(35.3 \%)$ & $3(8.8 \%)$ & $8(23.6 \%)$ & $3(8.8 \%)$ & $34(100 \%)$ \\
\hline Girls & $3(37.5 \%)$ & $2(25 \%)$ & $1(12.5 \%)$ & $1(12.5 \%)$ & $1(12.5 \%)$ & $8(100 \%)$ \\
\hline \multicolumn{7}{|c|}{ Table 6. Gender and Type of Psychiatric IIIness } \\
\hline
\end{tabular}

\section{DISCUSSION}

This study sampled 100 children and adolescents from juvenile homes in Kerala. Most of the children (86\%) were in the age group of 13-18 years. Boys constitute majority (73\%) of the sample. $42 \%$ of the inmates were found to have psychiatric illness which is consistent with the study conducted in Kenya by HM Maru et al $(2003)^{7}$ in which the crude psychiatric morbidity rate was $44.4 \%$. In the present study, $46.6 \%$ of the boys and $29.6 \%$ of the girls were found to have psychiatric illness which is consistent with the epidemiological study of detained juveniles in the United States in 2002 where two thirds of males and three quarters of females found to meet criteria for one or more psychiatric disorders (Teplin, Abram, McClelland, Dulcan \& Mericle, 2002). ${ }^{6}$ This finding is also consistent with the studies by Costello EJ et al(2003), ${ }^{2}$ Mousa Thabet AA and Vostanis P. (2001), ${ }^{3}$ and Premarajan et al (1993) ${ }^{4}$ where there were relatively more boys than girls being diagnosed as having mental disorders. Among the psychiatric illnesses, behavioural disorders and substance use disorders were found to be more in boys than in girls. $35.3 \%$ of boys and $25 \%$ of girls were found to have behavioural disorder. Emotional disorders were more in girls. $37.5 \%$ of girls and $23.5 \%$ of boys were suffering from emotional disorders. These findings are consistent with the Isle of Wight (IOW) study, Rutter et al, $(1970)^{1}$ and the Ontario Child Health Study (1987).10 In the Isle of Wight (IOW) study, it was found that emotional disorders were more common among girls with anxiety as the most common type. In the Ontario Child Health Study, the overall prevalence of psychiatric morbidity among children of 4-16 years age group was $18.1 \%$ and conduct disorder and hyperactivity were found more frequent in boys than in girls. Prevalence of emotional disorder was almost same for boys and girls $(10.2 \%$ vs. $10.7 \%$ respectively) in the $4-11$ years age group. But in children among 12-16 years age group, the rate of emotional disorder dropped to $4.9 \%$ for boys and increased to $13.6 \%$ for girls. The prevalence of somatisation disorders among 12-16 years age group was also significantly higher in girls $(10.7 \%)$ than boys (4.5\%). In the Puerto Rico study conducted among children of 4-17 years by Canino et al (2004),11 it was found that $19.8 \%$ of the sample met DSM-IV criteria for psychiatric disorders. The most prevalent disorders were behavioural disorders such as attention deficit hyperactivity disorder (8.0\%) and oppositional defiant disorder (5.5\%). As the age advances the rates of emotional disorders such as major depression and social phobia are increased, and younger age was related to higher rates of attention deficit hyperactivity disorder. Another study conducted in Kerala by Hacket et al (1999) ${ }^{5}$ among children in the age group 8-12 years found that externalising disorders were more in boys and were found to be associated with adverse social conditions.

\section{CONCLUSION}

The prevalence of psychiatric morbidity is high among inmates of juvenile homes. Behavioural disorders were found more in boys and emotional disorders were found more in girls. Boys were suffering from mental health disorders more compared to girls, but both boys and girls need mental health services equally. The provision of mental health services in such settings are inadequate. Children with psychiatric illness should receive appropriate interventions. This study presents certain basic data that can help the policy makers to understand the importance of mental health assessment and interventions in institutions such as juvenile homes.

\section{Recommendations}

Studies with larger sample size should be conducted in institutions like juvenile homes where children with special needs are placed. Studies to identify whether there is any relation between delinquent behaviour and psychiatric morbidity may help to understand these children more deeply and to make appropriate interventions so that the delinquent behaviour can be prevented by treating psychiatric illness.

\section{Limitations}

1. Small sample size.

2. No interventions were planned.

\section{REFERENCES}

[1] Rutter M, Tizard J, Whitmore K, (eds). Education, health and behavior. Longman, London 1970.

[2] Costello EJ, Mustillo S, Erkanli A, et al. Prevalence and development of psychiatric disorders in childhood and adolescence. Arch Gen Psychiatry 2003;60(8):837-44.

[3] Thabet MAA, Vostanis P. Epidemiology of child mental health problems in Gaza Strip. East Mediterr Health J 2001;7(3):403-12.

[4] Premarajan KC, Danabalan M, Chandrasekhar R, et al. Prevalence of psychiatric morbidity in an urban community of Pondicherry. Indian Journal of Psychiatry 1993;35(2):99-102.

[5] Hackett R, Hackett L, Bhakta P, et al. The prevalence and associations of psychiatric disorder in children in Kerala, South India. J Child Psychol Psychiatry 1999;40(5):801-7.

[6] Teplin LA, Abram KM, McClelland GM, et al. Psychiatric disorders in youth in juvenile detention. Arch Gen Psychiatry 2002;59(12):1133-43. 
[7] Maru HM, Kathuku DM, Ndetei DM. Psychiatric morbidity among children and young persons appearing in the Nairobi juvenile court, Kenya. East African Medical Journal 2003;80(6).

[8] Bhoge ND, Panse SN, Pawar AV, et al. A cross sectional study of psychiatric morbidity in juvenile boys admitted in an observation home. International Journal of Advances in Medicine 2017;4(1):192-7.

[9] Sedlak AJ, McPherson K. Survey of youth in residential placement: youth's needs and services. SYRP Report Rockville, MD: Westat 2010.
[10] Offord DR, Boyle MH, Szatmari P, et al. Ontario child health study-11 six-month prevalence of disorder and rates of service utilization. Arch Gen Psychiatry 1987;44(9):832-6.

[11] Canino G, Shrout PE, Rubio-Stipec M, et al. The DSM-IV rates of child and adolescent disorders in Puerto Rico: prevalence, correlates, service use, and the effects of impairment. Arch Gen Psychiatry 2004;61(1):85-93. 